

Western Washington University Western CEDAR

Summer 2015

\title{
Effect of Symbiotic State on the Fatty Acid Composition of Anthopleura elegantissima
}

Andrés J. Quesada

Western Washington University, quesadacr@gmail.com

Follow this and additional works at: https://cedar.wwu.edu/wwuet

Part of the Environmental Sciences Commons

\section{Recommended Citation}

Quesada, Andrés J., "Effect of Symbiotic State on the Fatty Acid Composition of Anthopleura elegantissima" (2015). WWU Graduate School Collection. 432.

https://cedar.wwu.edu/wwuet/432

This Masters Thesis is brought to you for free and open access by the WWU Graduate and Undergraduate Scholarship at Western CEDAR. It has been accepted for inclusion in WWU Graduate School Collection by an authorized administrator of Western CEDAR. For more information, please contact westerncedar@wwu.edu. 
EFFECT OF SYMBIOTIC STATE ON THE FATTY ACID COMPOSITION OF ANTHOPLEURA ELEGANTISSIMA

by

Andrés J. Quesada

Accepted in Partial Completion Of the Requirements for the Degree Master of Science

Kathleen L. Kitto, Dean of the Graduate School

ADVISORY COMMITTEE

Chair, Dr. Brian L. Bingham

Dr. Katherina Schoo

Dr. Brooke Love 


\section{MASTER'S THESIS}

In presenting this thesis in partial fulfillment of the requirements for a master's degree at Western Washington University, I grant to Western Washington University the non- exclusive royalty-free right to archive, reproduce, distribute, and display the thesis in any and all forms, including electronic format, via any digital library mechanisms maintained by WWU.

I represent and warrant this is my original work, and does not infringe or violate any rights of others. I warrant that I have obtained written permissions from the owner of any third party copyrighted material included in these files.

I acknowledge that I retain ownership rights to the copyright of this work, including but not limited to the right to use all or part of this work in future works, such as articles or books.

Library users are granted permission for individual, research and non-commercial reproduction of this work for educational purposes only. Any further digital posting of this document requires specific permission from the author.

Any copying or publication of this thesis for commercial purposes, or for financial gain, is not allowed without my written permission.

Andrés J. Quesada, June 15, 2015 


\section{EFFECT OF SYMBIOTIC STATE ON THE FATTY ACID COMPOSITION OF}

ANTHOPLEURA ELEGANTISSIMA

A Thesis Presented to

The Faculty of

Western Washington University

Accepted in Partial Completion

Of the Requirements for the Degree

Master of Science

by

Andrés J. Quesada

June 2015 


\section{ABSTRACT}

Anthopleura elegantissima, the most abundant intertidal sea anemone on the Pacific coast of North America, naturally occurs in three distinct symbiotic states: zooxanthellate (hosting the dinoflagellate Symbiodinium muscatinei), zoochlorellate (hosting the chlorophyte Elliptochloris marina), and aposymbiotic (lacking symbionts). S. muscatinei is more productive during summer months and may translocate considerably more carbon to the sea anemone host than does E. marina. Quantitative and qualitative differences in the contribution of energy from the symbiont are believed to affect host lipid levels, influencing growth and reproductive output. To study the effect of symbiotic state on host lipids in $A$. elegantissima, we collected ten specimens in each symbiotic state from the same habitat, separated symbiont and host tissues, and compared the fatty acid profiles of the two symbionts themselves, compared the fatty acid profiles of anemones in the three symbiotic states, and compared the profiles of the symbionts to their host anemones. We found significant differences in the fatty acid profiles of $S$. muscatinei and $E$. marina, with docosahexaenoic acid (DHA), oleic acid, and $\alpha$-linolenic acid contributing most to the differences. DHA was abundant in S. muscatinei, while E. marina contained high levels of oleic and $\alpha$-linolenic acids. We found higher total fatty acid content in zooxanthellate hosts than in zoochlorellate hosts, supporting previous research suggesting that $S$. muscatinei is a more favorable symbiont. We also found that aposymbiotic sea anemones had significantly lower concentrations of total fatty acids than symbiotic hosts and overall lower levels of all fatty acids, including polyunsaturated fatty acids (PUFAs). Because all the anemones came from 
the same habitat and should have had similar diets, and because cnidarians cannot synthesize PUFAs de novo, the depressed levels of fatty acids in aposymbiotic $A$. elegantissima suggest that these anemones deplete fatty acids faster due to the lack of symbiont photosynthate input. PUFAs play an important role in invertebrate growth and reproduction, so we expect symbiotic anemones to have higher fitness than aposymbiotic ones. Finally, although previous research suggests that symbionts translocate specific fatty acids to their cnidarian hosts, we found no evidence for fatty acid translocation in A. elegantissima. Our results reinforce the idea that hosting either type of symbiont increases the fitness of $A$. elegantissima, that hosting S. muscatinei may be more advantageous to the anemone, but do not support the hypothesis of fatty acid translocation between symbiont and host in this species. 


\section{ACKNOWLEDGEMENTS}

I would like to express my deepest appreciation and gratefulness to everyone who helped me complete this thesis. Brian Bingham provided exceptional guidance throughout the process. I am very thankful for his mentorship, kindness, understanding and relentless support. Katherina Schoo taught me how to conduct lipid analyses and exhibited selfless dedication to this project. Brooke Love participated in my thesis committee and made valuable observations that improved the manuscript. Jay Dimond taught me the methods to process sea anemones and generously shared his expertise on symbiosis. Charles Wandler and Erin Macri offered valuable assistance with the operation of the GCMS. Gene McKeen and Nathan Schwarck provided support with logistics, including laboratory use and sample collection.

This research was supported by grants from the National Science Foundation (NSF OCE-1260969 to Dr. Brian Bingham), Western Washington University Fund for the Enhancement of Graduate Research, Huxley Small Grant, and the North Cascades Audubon Society.

Felix, qui potuit rerum cognoscere causas. Fortunate [is he] who can know the causes of things.

-Virgil 


\section{TABLE OF CONTENTS}

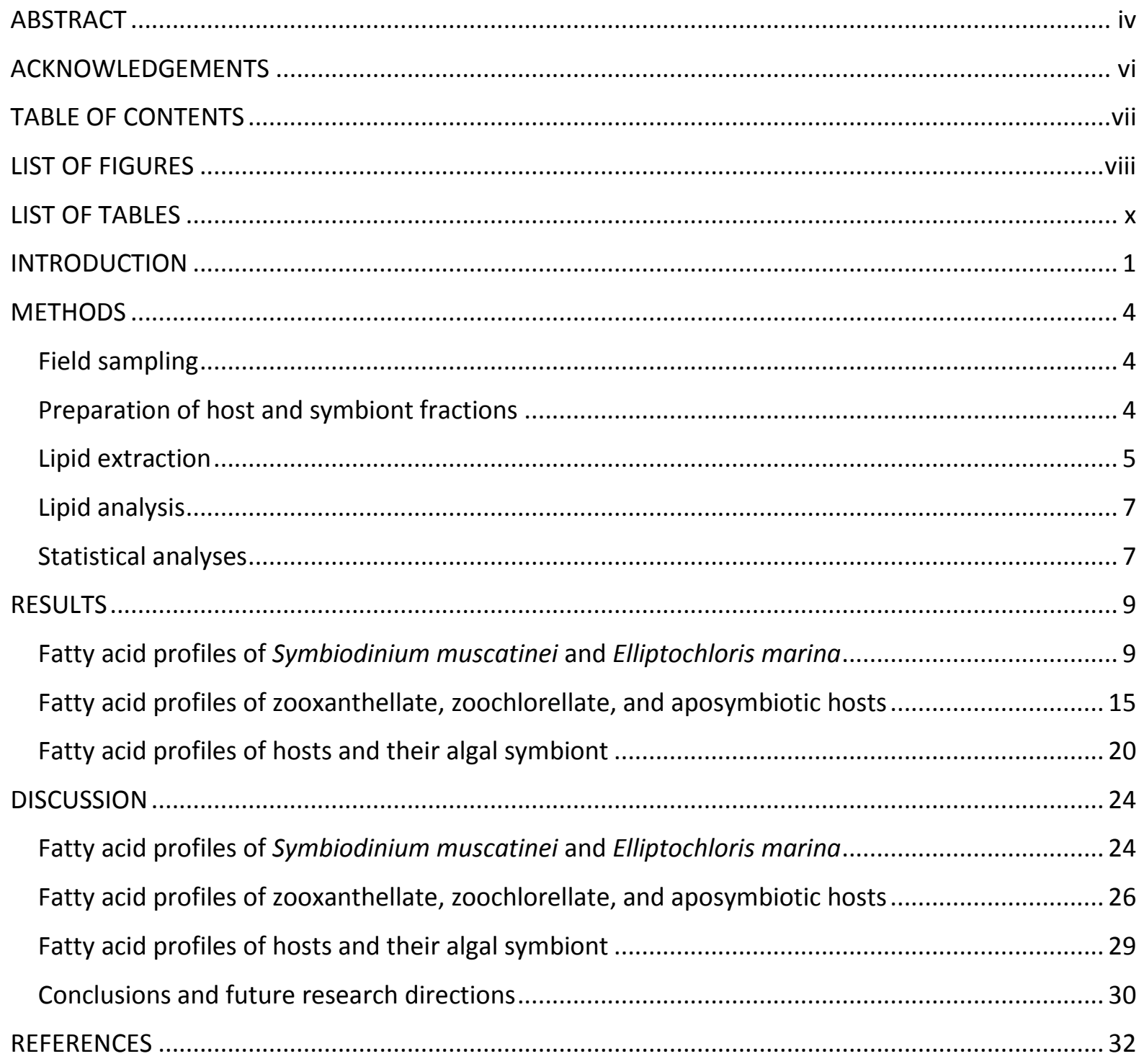




\section{LIST OF FIGURES}

Figure 1. Total fatty acid concentration in Symbiodinium muscatinei and Elliptochloris marina extracted from Anthopleura elegantissima and in the animal tissue only of zooxanthellate, zoochlorellate, and aposymbiotic Anthopleura elegantissima from Lawrence Point, Orcas Island. Standard error bars are shown.

Figure 2. Non-metric Multi-Dimensional Scaling (MDS) scatter plot of the fatty acid profiles of Symbiodinium muscatinei (yellow) and Elliptochloris marina (light green) extracted from Anthopleura elegantissima.....

Figure 3. Cluster analysis of the fatty acid profiles of Symbiodinium muscatinei and Elliptochloris marina extracted from Anthopleura elegantissima. Replicate numbers are shown after the species names.

Figure 4. Fatty acid composition and concentrations in Symbiodinium muscatinei and Elliptochloris marina extracted from zooxanthellate and zoochlorellate Anthopleura elegantissima collected at Lawrence Point, Orcas Island. Fatty acids are ordered by length of the carbon chain. Standard error bars are shown.

Figure 5. Non-metric Multi-Dimensional Scaling (MDS) scatter plot of the lipid profiles from Anthopleura elegantissima in the three symbiotic states: zooxanthellate (brown), zoochlorellate (green), aposymbiotic (grey). Data were for the animal portions alone with the symbionts removed.

Figure 6. Cluster analysis of the lipid profiles from Anthopleura elegantissima in the three symbiotic states: zooxanthellate (brown), zoochlorellate (green), and aposymbiotic (grey).

Figure 7. Fatty acid composition and concentration in animal tissues of zooxanthellate, zoochlorellate, and aposymbiotic Anthopleura elegantissima from Lawrence Point, Orcas Island. Fatty acids are ordered by length of the carbon chain. Standard error bars are shown. .20

Figure 8. Non-metric Multi-Dimensional Scaling (MDS) scatter plot of the lipid profiles of zooxanthellate (brown) and zoochlorellate Anthopleura elegantissima (dark green) and their symbionts Symbiodinium muscatinei (yellow) and Elliptochloris marina (light green) from Anthopleura elegantissima. .22

Figure 9. Fatty acid composition and concentration of Symbiodinium muscatinei and zooxanthellate Anthopleura elegantissima from Lawrence Point, Orcas Island. Fatty acids are ordered by length of the carbon chain. Standard error bars are shown. 
Figure 10. Fatty acid composition and concentration of Elliptochloris marina and zoochlorellate Anthopleura elegantissima from Lawrence Point, Orcas Island. Fatty acids are ordered by length of the carbon chain. Standard error bars are shown...................................24 


\section{LIST OF TABLES}

Table 1. Fatty acids contributing to the differences between Symbiodinium muscatinei and Elliptochloris marina extracted from Anthopleura elegantissima from Lawrence Point, Orcas Island, as indicated by SIMPER analyses. Significant statistical tests are reported

Table 2. Fatty acids contributing to the differences between zooxanthellate, zoochlorellate and aposymbiotic Anthopleura elegantissima from Lawrence Point, Orcas Island, as indicated by SIMPER analyses. Statistical tests are reported .19 


\section{INTRODUCTION}

Many cnidarians associate symbiotically with autotrophic, unicellular, dinoflagellate algae of the genus Symbiodinium (commonly called zooxanthellae), that provide them with photosynthetic products such as glucose, glycerol, amino acids and lipids (Yellowlees et al. 2008). Research suggests that the interaction between cnidarians and their endosymbiotic algae is not always mutualistic, but rather a continuum, ranging from parasitism to mutualism (Lesser et al. 2013). The nature of the relationship may be determined by the identity of the symbiont. For example, Mieog et al. (2009) found that growth, survival, and thermal tolerance of a tropical coral is determined by the Symbiodinium clade hosted. Another study showed that hosting clade A Symbiodinium, which fix less carbon than clade C, may reduce host fitness by not providing enough carbon to meet the host's nutritional requirements (Stat et al. 2008). Loram et al. (2007) found that sea anemones harboring clade A Symbiodinium incorporated more photosynthesisfixed carbon into lipids and less into sugars and amino acids, compared to individuals hosting clade B symbionts. These quantitative and qualitative differences in the contribution of energy from the symbiont are believed to affect host lipid levels, in turn influencing host growth and reproductive output (Stimson 1987; Ward 1995; Leuzinger et al. 2003).

A growing body of evidence indicates that lipids play an important role in cnidarian-algal symbioses. For example, research has shown that Symbiodinium cells and cnidarian cells hosting Symbiodinium accumulate wax esters, triglycerides, sterols, phospholipids, and fatty acids in organelles called lipid bodies (Peng et al. 2011; Chen et al. 2011; Jiang et al. 2014; Pasaribu et al. 2014). Kopp et al. (2015) found that zooxanthellae cells in corals turn inorganic bicarbonate and nitrates into lipid droplets and glycogen. These photosynthates accumulate in the zooxanthellae 
when exposed to light, showing that production of lipid droplets is linked to photosynthesis. The size and density of these lipid bodies is positively correlated with solar irradiation (Peng et al. 2012). Luo et al. (2009) suggest that "lipid trafficking" between symbiont and host lipid bodies plays a role in regulating the endosymbiosis. It is also believed that fatty acids produced by algal symbionts are translocated to their cnidarian hosts (e.g. Papina et al. 2003; Treignier et al. 2008; Imbs et al. 2014), with the presence of dinoflagellate fatty acid markers (i.e. fatty acids that can be synthesized by algae but not by animals) in cnidarian host tissue as evidence for translocation (Papina et al. 2003; Papina et al. 2007). Other authors have cited similarities in the relative proportions of fatty acids in zooxanthellae and host tissue as evidence for translocation (Treignier et al. 2008; Mortillaro et al. 2009; Imbs et al. 2011; Imbs et al. 2014). However, it should be noted that fatty acids and fatty acid markers can also be obtained through the diet, so the evidence for translocation to date remains inconclusive.

Anthopleura elegantissima is the most abundant intertidal sea anemone on the Pacific coast of North America and has been extensively used as a symbiosis research subject because individuals naturally occur in three distinct symbiotic states: zooxanthellate (hosting the dinoflagellate Symbiodinium muscatinei), zoochlorellate (hosting the chlorophyte Elliptochloris marina), and aposymbiotic (lacking symbionts) (LaJeunesse and Trench 2000; Lewis and MullerParker 2004). The two symbionts are taxonomically, ecologically, morphologically, and metabolically different. E. marina is negatively affected by high light and temperatures (Verde and McCloskey 2001; 2002), so zoochlorellate A. elegantissima are restricted to cooler, shaded sites, whereas zooxanthellate sea anemones occur in areas with more sunlight (Secord and Muller-Parker 2005). When in symbiosis with A. elegantissima, E. marina is about four times 
more abundant and grows up to eight times faster than S. muscatinei, but has about half the volume, half the carbon content per cell, and less chlorophyll (Verde and McCloskey 1996; Bergschneider and Muller-Parker 2008). Research suggests that S. muscatinei is a more favorable symbiont, because its productivity during summer months is about 2.5 times greater than that of E. marina (Bergschneider and Muller-Parker 2008) and its population potentially translocates up to five times more carbon to the sea anemone (Verde and McCloskey 1996). However, Engebretson and Muller-Parker (1999) suggest that the total amount of carbon translocated to the host may be similar for both symbionts, mainly due to the greater density of E. marina. Hence it is unclear whether the greater productivity of S. muscatinei translates into higher rates of translocation and improved host performance. Nor is it known whether the two symbiont species transfer the same photosynthetic products to their hosts, which seems unlikely given their taxonomic differences.

The main goal of our study was to understand how symbiotic state affects fatty acid composition in A. elegantissima. Our specific approaches were, (i) to compare the fatty acid profiles of the symbionts S. muscatinei and E. marina themselves, (ii) to compare the fatty acid profiles of $A$. elegantissima in the three symbiotic states looking for differences in fatty acid concentration and composition that might produce fitness differences, and (iii) to compare the fatty acid profiles of the symbionts to their host sea anemones to determine similarities in fatty acid concentration and composition that may indicate translocation. 


\section{METHODS}

\section{Field sampling}

Zooxanthellate, zoochlorellate, and aposymbiotic A. elegantissima were collected from Lawrence Point, Orcas Island on 26 June, 2014, in early summer, when studies demonstrate considerable differences in symbiont productivity due to high solar radiation and temperature (Bergschneider and Muller-Parker 2008). Ten specimens in each of the three symbiotic states were collected haphazardly from roughly the same tidal height ( 0 to $+.5 \mathrm{~m} \mathrm{MLLW}$ ) within an area of approximately $30 \mathrm{~m}^{2}$. Presumably, sea anemones in this limited area the same location and tidal height capture similar prey items, and might be expected to have similar lipid profiles if symbionts have no effect on the lipid composition of their host.

Specimens were collected by removing them from the rocky surface with a small spatula, placing them in a ziptop bag, and storing them in a bucket of seawater. The anemones were transported to Shannon Point Marine Center (SPMC), in Anacortes, WA where they were placed in individual glass dishes submerged in sea tables with running seawater. They were held for 96 $\mathrm{h}$ to allow them to empty their gut contents, ensuring that all fatty acids extracted were from the sea anemones themselves and not from ingested prey.

\section{Preparation of host and symbiont fractions}

To permit comparison of the lipid profiles of symbionts and hosts, it was important to separate the algal symbionts from the sea anemone gastrodermal cells housing them. This was accomplished through homogenization and centrifugation. The sea anemones were cleared of any attached debris, then placed in a blender cup with $10-15 \mathrm{~mL}$ of filtered seawater and 
homogenized for 30 seconds. The homogenate was poured into borosilicate glass test tubes and centrifuged for 2 minutes at high speed. This rendered a supernatant containing the host fraction and a pellet comprised of symbiont cells and a small amount of host material (mostly mesoglea). The supernatant was transferred to a new test tube and centrifuged again. This was repeated a third time to remove any remaining symbionts and the cleaned supernatant, containing only host cells, was pipetted into a $50 \mathrm{~mL}$ centrifuge tube and stored at $-80^{\circ} \mathrm{C}$.

A clean symbiont fraction was obtained by taking the pellet from the initial centrifugation through several washes and filtrations to remove any remaining host cells. The cells were resuspended by adding filtered seawater to the pellet and vortexing for 5 seconds. The mixture was centrifuged for 2 minutes at high speed and the supernatant, which contained small amounts of anemone mesoglea, was discarded. This procedure was repeated twice more to thoroughly wash the symbionts and remove remaining host material. The symbionts were resuspended in filtered seawater then forced through a filter syringe with a $100 \mu \mathrm{m}$ Nitex mesh into a new test tube. The clean symbiont fraction was then transferred to a $15 \mathrm{~mL}$ centrifuge tube, and stored at $-80^{\circ} \mathrm{C}$. After being frozen for at least two days, both the animal fractions and cleaned symbionts were freeze dried at $-50^{\circ} \mathrm{C}$ for 48 hours.

\section{Lipid extraction}

Fatty acid extractions were based on a modification of the methods of Folch et al. (1957) and Bligh and Dyer (1959). Preliminary tests showed that approximately $20 \mathrm{mg}$ of freeze dried tissue was optimal for our lipid extraction protocol and analyses. To initiate the extraction, 20-25 $\mathrm{mg}$ of freeze dried sea anemone (from a single individual) or symbiont (extracted from a single 
anemone) was added to individual test tubes. The exact mass was noted to standardize the fatty acid concentrations in all samples to $20 \mathrm{mg}$. An internal fatty acid standard of nonadecanoic acid (19:0C) in a 2:1 (vol:vol) dichloromethane/methanol solution was added along with $4 \mathrm{~mL}$ of 2:1 dichloromethane/methanol. The mixture was flushed with nitrogen gas and placed in a freezer for $48 \mathrm{~h}$ at $-80^{\circ} \mathrm{C}$.

After $48 \mathrm{~h}$, the samples were removed from the freezer and thawed. To precipitate any sediment from these samples, the test tubes were vortexed for 3-5 seconds and centrifuged at $3500 \mathrm{RPM}$ for $10 \mathrm{~min}$ at $5^{\circ} \mathrm{C}$. The solutions were then transferred to new test tubes, leaving any sediment behind. Immediately, $2 \mathrm{~mL}$ of $0.88 \% \mathrm{KCl}$ buffer was added to all test tubes, which were then shaken, vortexed, and centrifuged at 3500 RPM for $10 \mathrm{~min}$ at $5^{\circ} \mathrm{C}$. The addition of the buffer resulted in two layers: an upper water-soluble fraction containing contaminants and a lower organic fraction containing the purified lipids. The top layer was discarded and the lower layer was transferred to a new test tube. The test tubes were quickly placed in a nitrogen evaporator (Organomation Associates N-EVAP) and the samples were evaporated using a steady flow of nitrogen gas. Once the sample was completely evaporated, $3 \mathrm{~mL}$ of methanolic-sulphuric acid was added and the samples were flushed with nitrogen gas. The test tubes were then placed in a heating block at $70^{\circ} \mathrm{C}$ to esterify the fatty acids. After 60 minutes, the test tubes were moved to a cooling rack, then $2 \mathrm{~mL}$ of hexane was added to wash the fatty acids from the methanolicsulphuric acid and the test tubes were vortexed and centrifuged. This again produced two layers. The upper layer, which contained the fatty acid methyl esters, was transferred to a $2 \mathrm{~mL}$ vial that was placed in the nitrogen evaporator. As the samples were being evaporated with nitrogen gas, another $2 \mathrm{~mL}$ of hexane was added to the remaining layer, which was vortexed and centrifuged 
again. The new upper layer was combined with the previous upper layer and the solution was evaporated completely in the nitrogen evaporator. Finally, $100 \mu \mathrm{L}$ of hexane was added, the vial was flushed with nitrogen gas, closed tightly, sealed with Teflon tape, and stored at $-80^{\circ} \mathrm{C}$ until analysis.

Lipid analysis

All samples were analyzed in a Varian CP3800 Gas Chromatograph with a Saturn 2000 lon Trap Mass Spectrometer. Fatty acid methyl esters (FAMEs) were separated with an Agilent HP88 capillary column with helium as the carrier gas. After injection at $60^{\circ} \mathrm{C}$, the temperature was held for one minute then increased to $150^{\circ} \mathrm{C}$ at a rate of $15^{\circ} \mathrm{C}$ per minute, to $170^{\circ} \mathrm{C}$ at $3^{\circ} \mathrm{C}$ per minute, to $190^{\circ} \mathrm{C}$ at $1^{\circ} \mathrm{C}$ per minute, to $240^{\circ} \mathrm{C}$ at $20^{\circ} \mathrm{C}$ per minute, and finally held constant for 20 minutes. FAMEs were identified via mass spectrometry by comparing their retention times with a Supelco 37 Component FAME Mix (Sigma-Aldrich) and verified with the NIST Mass Spectral Library. FAME concentrations were calculated by converting the area of the fatty acid peaks in the mass chromatogram to weight using the known nonadecanoic acid internal standard as a reference. The weights of arachidonic acid and erucic acid were pooled for the S. muscatinei and E. marina samples because the peaks could not be separated. One of the zooxanthellate sea anemone host samples was omitted from the analyses due to unreliable peaks.

\section{$\underline{\text { Statistical analyses }}$}

We used PAST 3.04 (Hammer et al. 2001) for all statistical analyses. Our first goal was to compare the fatty acid profiles of the symbionts E. marina and S. muscatinei. First, we used a 
one-way ANOVA to determine if either symbiont contained significantly more total fatty acids. We then used MDS and paired-group cluster analyses to detect which samples were most similar. After MDS, we used an ANOSIM test to detect significant differences in fatty acid composition between the two symbiont species and a SIMPER test to detect which fatty acids contributed most to any differences. We used Euclidean distance as the distance metric and square root transformed the data to prevent the most abundant fatty acids from dominating the analyses. Following SIMPER, we used one-way ANOVA's or Mann-Whitney $U$ tests (if data did not follow a normal distribution) to statistically compare the concentrations of fatty acids that contributed most to the separation of groups.

Our second goal was to compare the fatty acid profiles of hosts in the three symbiotic states (zooxanthellate, zoochlorellate, and aposymbiotic). As with the symbionts, we used oneway ANOVA's or Mann-Whitney $U$ tests to compare total fatty concentrations, MDS and pairedgroup cluster analyses to detect differences among samples, ANOSIM tests to test treatment differences, then SIMPER to identify fatty acids that contributed most to any differences. The concentrations of fatty acids that contributed most to the separation between groups were statistically compared with one-way ANOVA's or Mann-Whitney U tests.

Our third goal was to compare the fatty acid profiles of the symbionts to their host sea anemones. We again used MDS to detect differences among samples and an ANOSIM test, this time to detect significant differences in fatty acid composition between symbionts and their hosts. This was done separately for S. muscatinei and their hosts, then for E. marina and their hosts. We then used Pearson correlation analyses and Spearman rank correlation analyses (if data did not follow a normal distribution) to look for linear relationships between the 
concentrations of each fatty acid in the symbionts and in their hosts, which may be indicative of fatty acid translocation.

\section{RESULTS}

Fatty acid profiles of Symbiodinium muscatinei and Elliptochloris marina

Contrary to our expectations, E. marina had a significantly higher concentration of fatty acids than did S. muscatinei (one-way ANOVA, $F_{1,18}=10.06, p=0.005$, Fig. 1), and MDS and cluster analyses showed a clear separation of E. marina and S. muscatinei based on fatty acid profiles (Figs. 2-3). ANOSIM showed that the differences were statistically significant $(R=0.96, p<0.05)$ and SIMPER showed that cis-4,7,10,13,16,19-docosahexaenoic acid (DHA), oleic acid, and $\alpha$ linolenic acid contributed most to differences between the symbiont species (Table 1).

The overall most common fatty acids, oleic, palmitic, and $\alpha$-linolenic, were all more concentrated in E. marina than in S. muscatinei (Fig. 4). Oleic acid was over three times more concentrated and $\alpha$-linolenic over six times more concentrated in E. marina. Interestingly, DHA was over four times more concentrated in S. muscatinei, being detected in only in two samples of E. marina, but in all S. muscatinei. Myristoleic acid and behenic acid were detected only in S. muscatinei. 


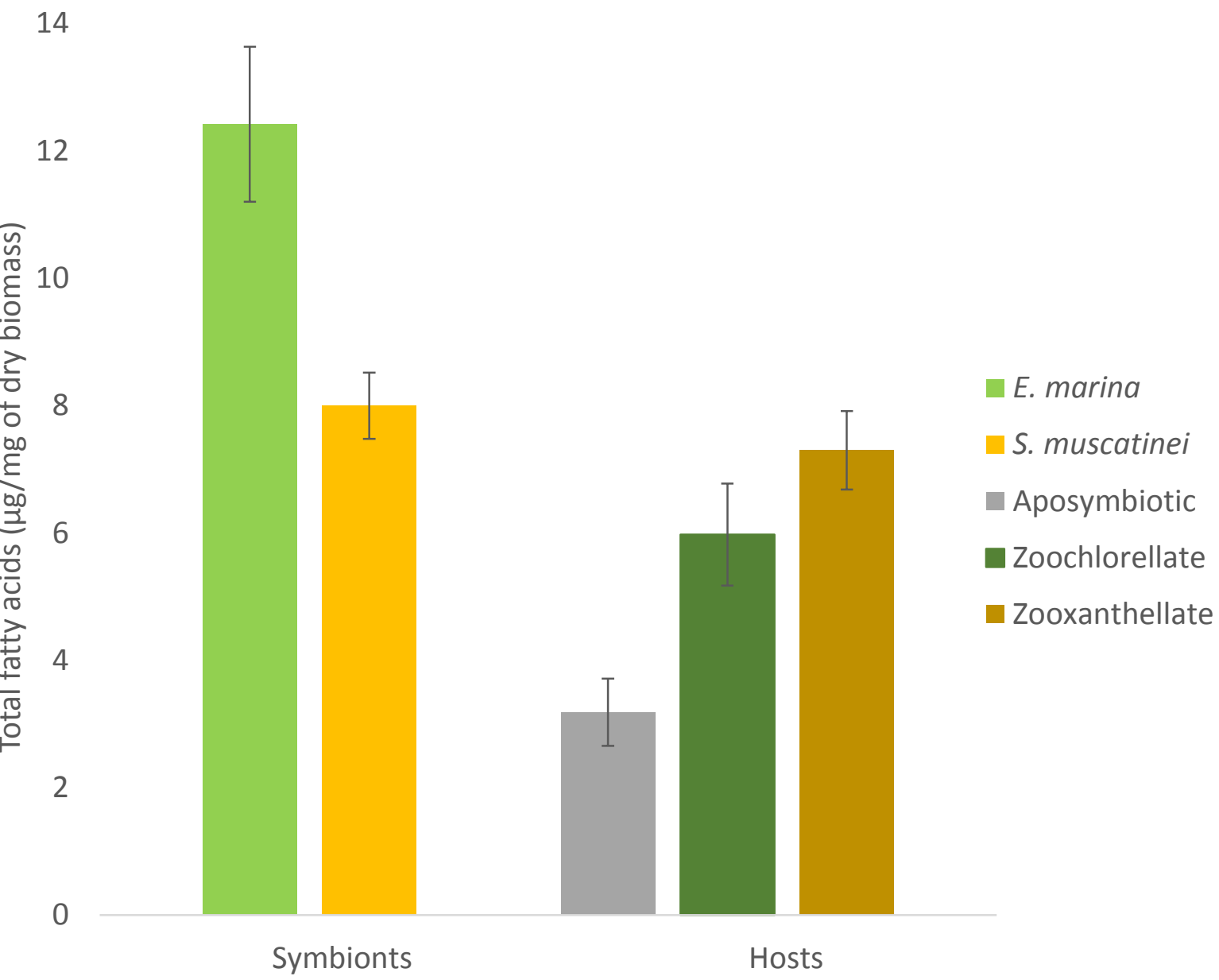

Figure 1. Total fatty acid concentration in Symbiodinium muscatinei and Elliptochloris marina extracted from Anthopleura elegantissima and in the animal tissue only of zooxanthellate, zoochlorellate, and aposymbiotic Anthopleura elegantissima from Lawrence Point, Orcas Island. Standard error bars are shown. 
stress $=0.05$

E. marina

S. muscatinei

Figure 2. Non-metric Multi-Dimensional Scaling (MDS) scatter plot of the fatty acid profiles of Symbiodinium muscatinei (yellow) and Elliptochloris marina (light green) extracted from Anthopleura elegantissima. 


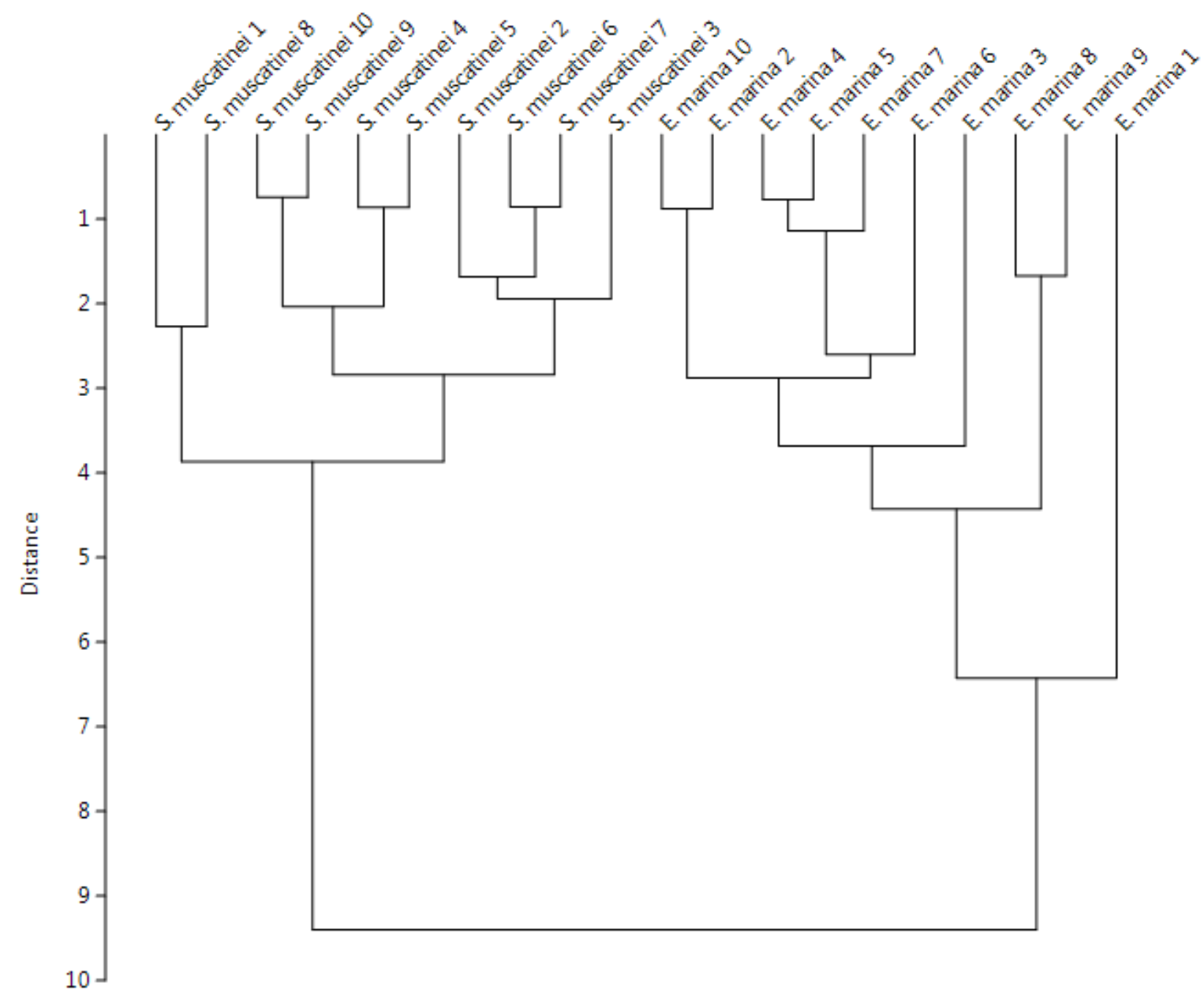

Figure 3. Cluster analysis of the fatty acid profiles of Symbiodinium muscatinei and Elliptochloris marina extracted from Anthopleura elegantissima. Replicate numbers are shown after the species names. 
Table 1. Fatty acids contributing to the differences between Symbiodinium muscatinei and Elliptochloris marina extracted from Anthopleura elegantissima from Lawrence Point, Orcas Island, as indicated by SIMPER analyses. Significant statistical tests are reported.

\begin{tabular}{llcccc}
\hline Groups compared & Fatty acid & Contribution (\%) & $\boldsymbol{F}(\boldsymbol{p})$ & $\boldsymbol{U}(\boldsymbol{p})$ & $\boldsymbol{d} \boldsymbol{f}$ \\
\hline S. muscatinei vs. & DHA & 35.8 & & $0(0.0001)$ & 1,18 \\
E. marina & Oleic & 26.6 & & $0(0.0002)$ & 1,18 \\
& a-linolenic & 22.7 & $68.25(<0.0001)$ & & 1,18 \\
& Myristic & 3.8 & & $0(0.0001)$ & 1,18 \\
& Palmitic & 3.1 & $6.71(0.02)$ & & 1,18 \\
\hline
\end{tabular}






Figure 4. Fatty acid composition and concentrations in Symbiodinium muscatinei and Elliptochloris marina extracted from zooxanthellate and zoochlorellate Anthopleura elegantissima collected at Lawrence Point, Orcas Island. Fatty acids are ordered by length of the carbon chain. Standard error bars are shown. 
Fatty acid profiles of zooxanthellate, zoochlorellate, and aposymbiotic hosts

Fatty acid levels in aposymbiotic sea anemones were significantly lower than in zoochlorellate (one-way ANOVA, $F_{1,18}=7.87, p=0.01$ ) and zooxanthellate hosts from which the symbionts had been removed (Mann-Whitney $U_{1,17}=2, p=0.0005$ ). However, we found no significant differences between zoochlorellate and zooxanthellate sea anemones themselves (Fig. 1). Despite some overlap in the MDS and cluster analyses of samples from hosts in these three symbiotic states (Figs. 5-6), ANOSIM show significant differences between zooxanthellate and zoochlorellate hosts $(R=0.24, p<0.05)$, between zooxanthellate and aposymbiotic hosts $(R=0.75, p<0.05)$, and between zoochlorellate and aposymbiotic hosts $(R=0.37, p<0.05)$. The main fatty acids contributing to the differences between hosts in different symbiotic states were linoleic acid, palmitoleic acid, elaidic acid, DHA, and EPA (Table 2).

Our data indicate that nearly every fatty acid was more concentrated in zooxanthellate than in zoochlorellate host tissues, and that aposymbiotic sea anemones had lower concentrations of every single fatty acid than hosts in either symbiotic condition (Fig. 7). In several cases, the concentration of fatty acids in symbiotic hosts doubled that of hosts lacking symbionts. Pentadecanoic acid was only detected in zooxanthellate hosts and $\alpha$-linolenic was only detected in zoochlorellate hosts, although both in very low concentrations. We did not detect myristic, palmitoleic, or linoleic acids in aposymbiotic anemones. 


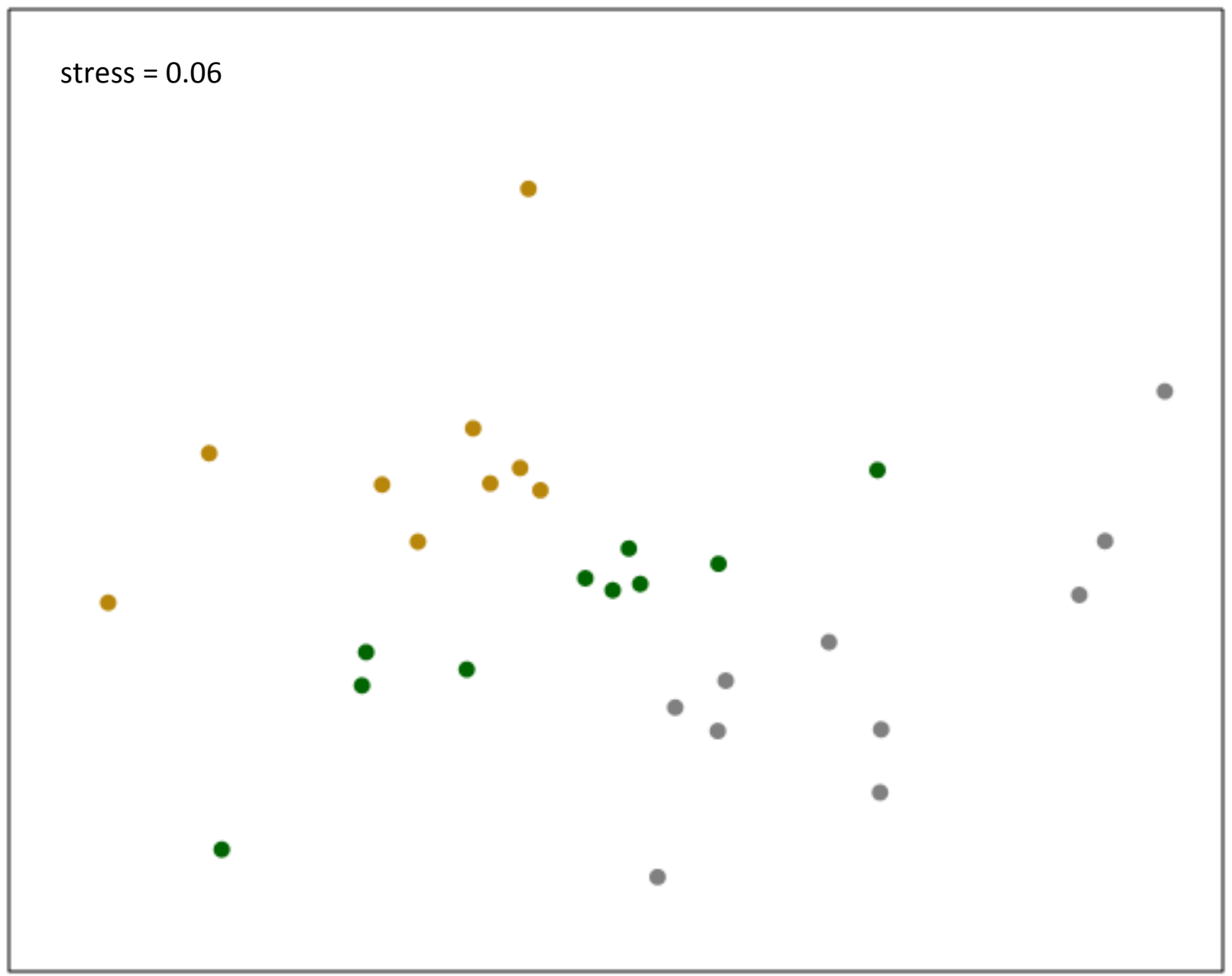

Figure 5. Non-metric Multi-Dimensional Scaling (MDS) scatter plot of the lipid profiles from Anthopleura elegantissima in the three symbiotic states: zooxanthellate (brown), zoochlorellate (green), aposymbiotic (grey). Data were for the animal portions alone with the symbionts removed. 


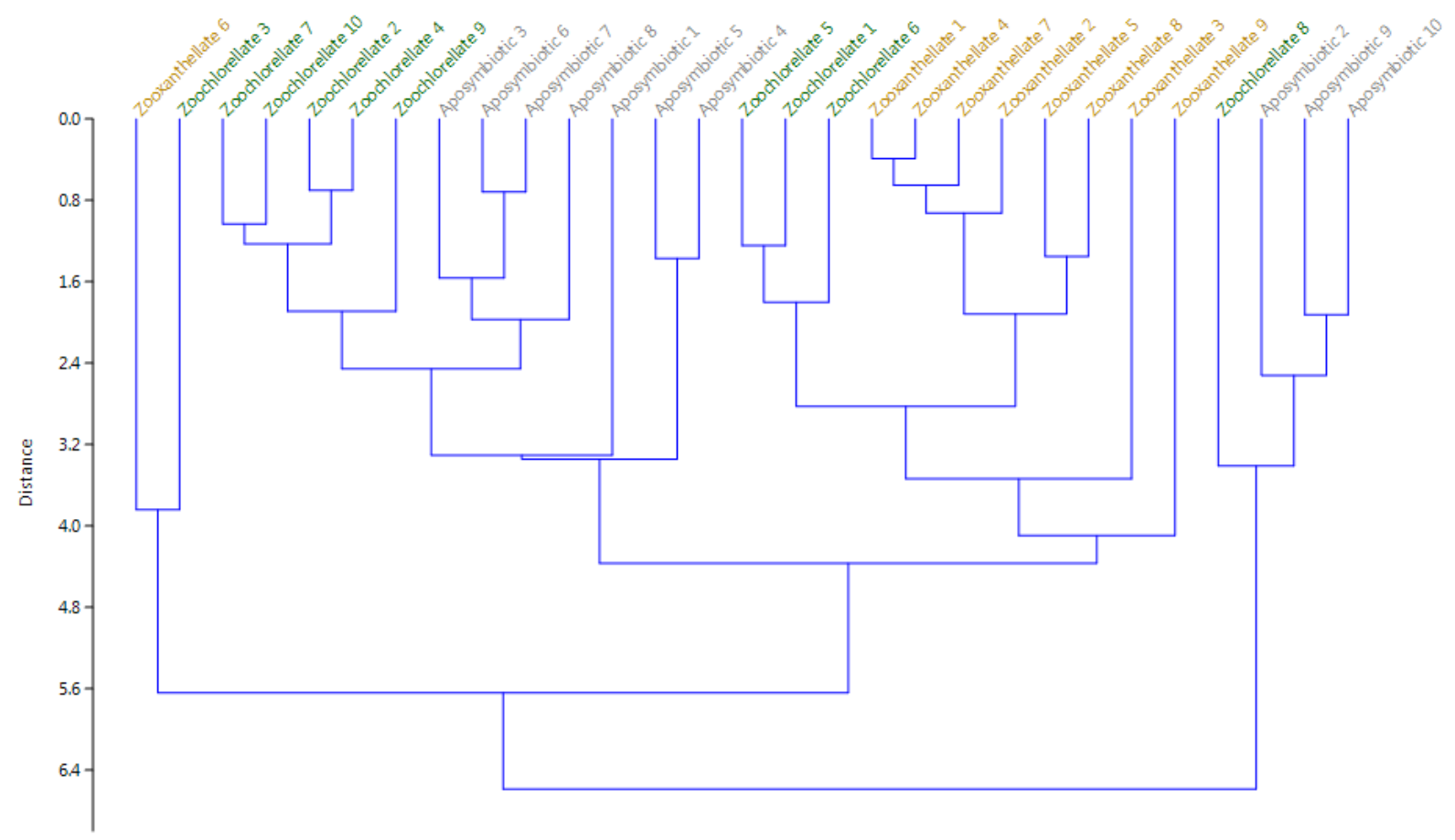

Figure 6. Cluster analysis of the lipid profiles from Anthopleura elegantissima in the three symbiotic states: zooxanthellate (brown), zoochlorellate (green), and aposymbiotic (grey). 
Table 2. Fatty acids contributing to the differences between zooxanthellate, zoochlorellate and aposymbiotic Anthopleura elegantissima from Lawrence Point, Orcas Island, as indicated by SIMPER analyses. Statistical tests are reported.

\begin{tabular}{llcccc}
\hline Groups compared & Fatty acid & Contribution $(\%)$ & $\boldsymbol{F}(\boldsymbol{p})$ & $\boldsymbol{U}(\boldsymbol{p})$ & $\boldsymbol{d f}$ \\
\hline Zooxanthellate vs. & Linoleic & 13.9 & & $0(0.0002)$ & 1,17 \\
zoochlorellate & Palmitoleic & 10.8 & $38.73(<0.0001)$ & & 1,17 \\
& EPA & 9.9 & & $33(0.35)$ & 1,17 \\
& DHA & 9.7 & $0.038(0.85)$ & & 1,17 \\
& Elaidic & 7.5 & $11.42(0.004)$ & & 1,17 \\
& Palmitic & 7.4 & & $19(0.04)$ & 1,17 \\
Aposymbiotic vs. & Elaidic & 20.8 & $87.23(<0.0001)$ & & \\
zooxanthellate & Palmitoleic & 11.2 & & $0(<0.0001)$ & 1,17 \\
& EPA & 9.8 & & $8(0.003)$ & 1,17 \\
& DHA & 9.0 & $9.6(0.007)$ & & 1,17 \\
& Linolelaidic & 8.3 & & $0(0.0002)$ & 1,17 \\
& Oleic & 7.2 & & $1(0.0004)$ & 1,17 \\
& Palmitic & 7.1 & & $9(0.004)$ & 1,17 \\
& & & & & 1,18 \\
Aposymbiotic vs. & Elaidic & 16.7 & $38.69(<0.0001)$ & & 1,18 \\
zoochlorellate & EPA & 14.1 & $5.67(0.02)$ & & 1,18 \\
& DHA & 13.8 & $6.07(0.02)$ & $0(0.0001)$ & 1,18 \\
& Linolelaidic & 8.3 & & & 1,18 \\
& Erucic & 7.3 & $11.32(0.003)$ & & 1,18 \\
\hline
\end{tabular}




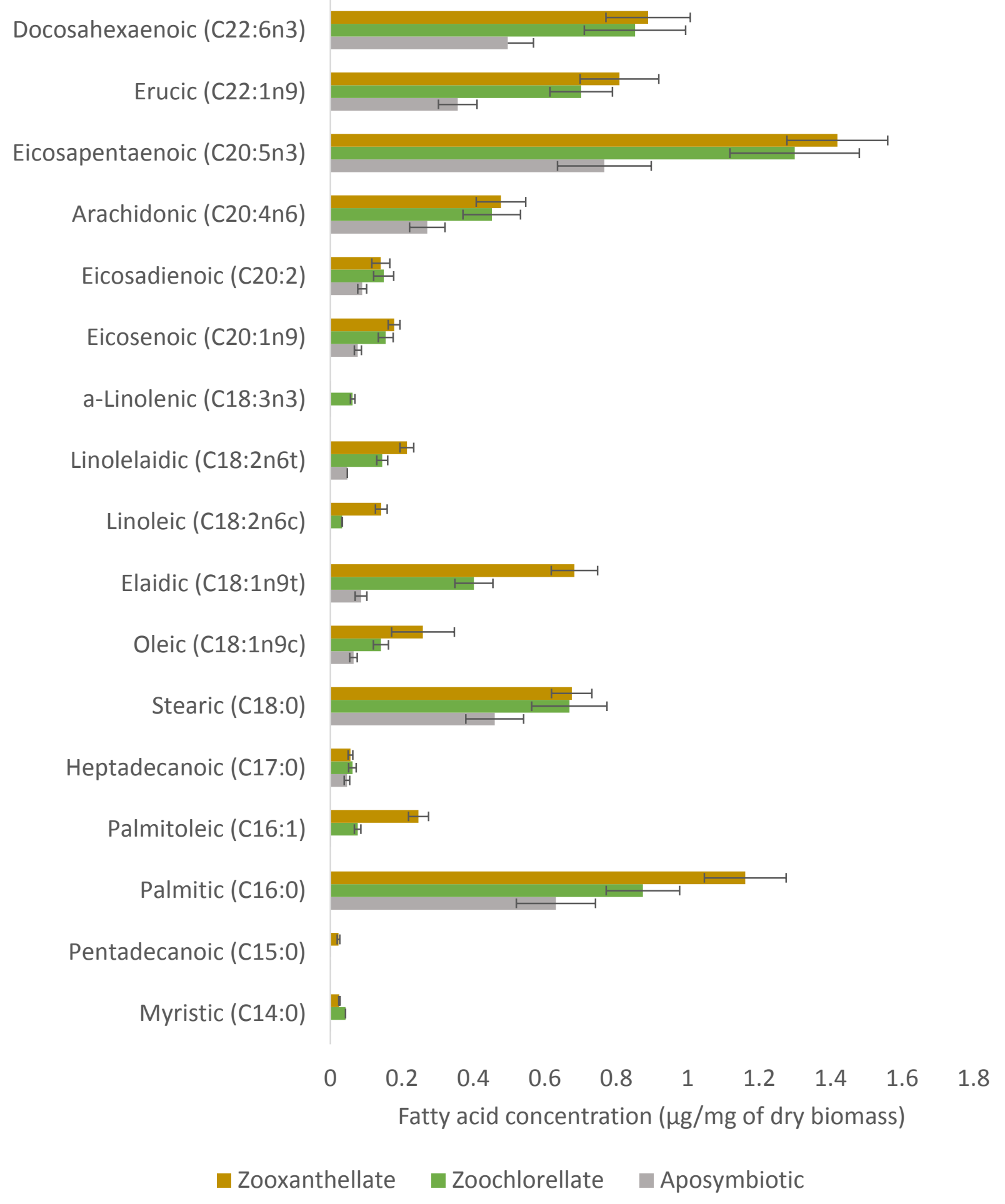

Figure 7. Fatty acid composition and concentration in animal tissues of zooxanthellate, zoochlorellate, and aposymbiotic Anthopleura elegantissima from Lawrence Point, Orcas Island. Fatty acids are ordered by length of the carbon chain. Standard error bars are shown. 


\section{Fatty acid profiles of hosts and their algal symbiont}

We found significant differences in the fatty acid profiles of zooxanthellate hosts and their symbiont S. muscatinei (ANOSIM, R=1, $\mathrm{p}<0.05$ ) and between zoochlorellate hosts and their symbiont E. marina (ANOSIM, $\mathrm{R}=1, \mathrm{p}<0.05$ ). The $\mathrm{MDS}$ showed more similarity between zoochlorellate and zooxanthellate host tissues than between the S. muscatinei and E. marina (Fig. 8). Few fatty acids were found in high levels in both hosts and their symbionts (Figs. 9-10). Palmitoleic acid, oleic acid, and a-linolenic acid were concentrated in the both symbionts, but scarce or absent in the hosts, whereas EPA, arachidonic, and erucic were concentrated in the hosts, but not in the symbionts. DHA was considerably more concentrated in S. muscatinei than in E. marina, but its levels were almost identical in zooxanthellate and zoochlorellate sea anemones.

We found a significant positive correlation between S. muscatinei and zooxanthellate hosts only in the concentrations of linoleic acid (Pearson, $r=0.76, p=0.02$ ). However, we found significant positive correlations in the concentrations of palmitic acid (Pearson, $r=0.75, p=0.01$ ), palmitoleic acid (Spearman, $r=0.44, p=0.04$ ), and oleic acid (Pearson, $r=0.75, p=0.01$ ) between $E$. marina and zoochlorellate hosts (Table 3). 
stress $=0.05$

S. muscatinei

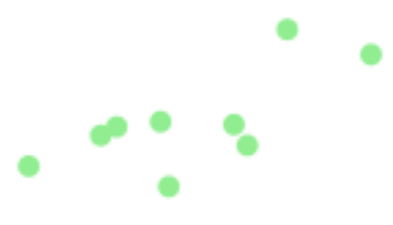

E. marina
Zooxanthellate

A. elegantissima

-

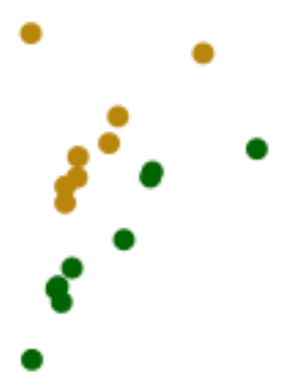

- Zoochlorellate
A. elegantissima

Figure 8. Non-metric Multi-Dimensional Scaling (MDS) scatter plot of the lipid profiles of zooxanthellate (brown) and zoochlorellate Anthopleura elegantissima (dark green) and their symbionts Symbiodinium muscatinei (yellow) and Elliptochloris marina (light green) from Anthopleura elegantissima. 


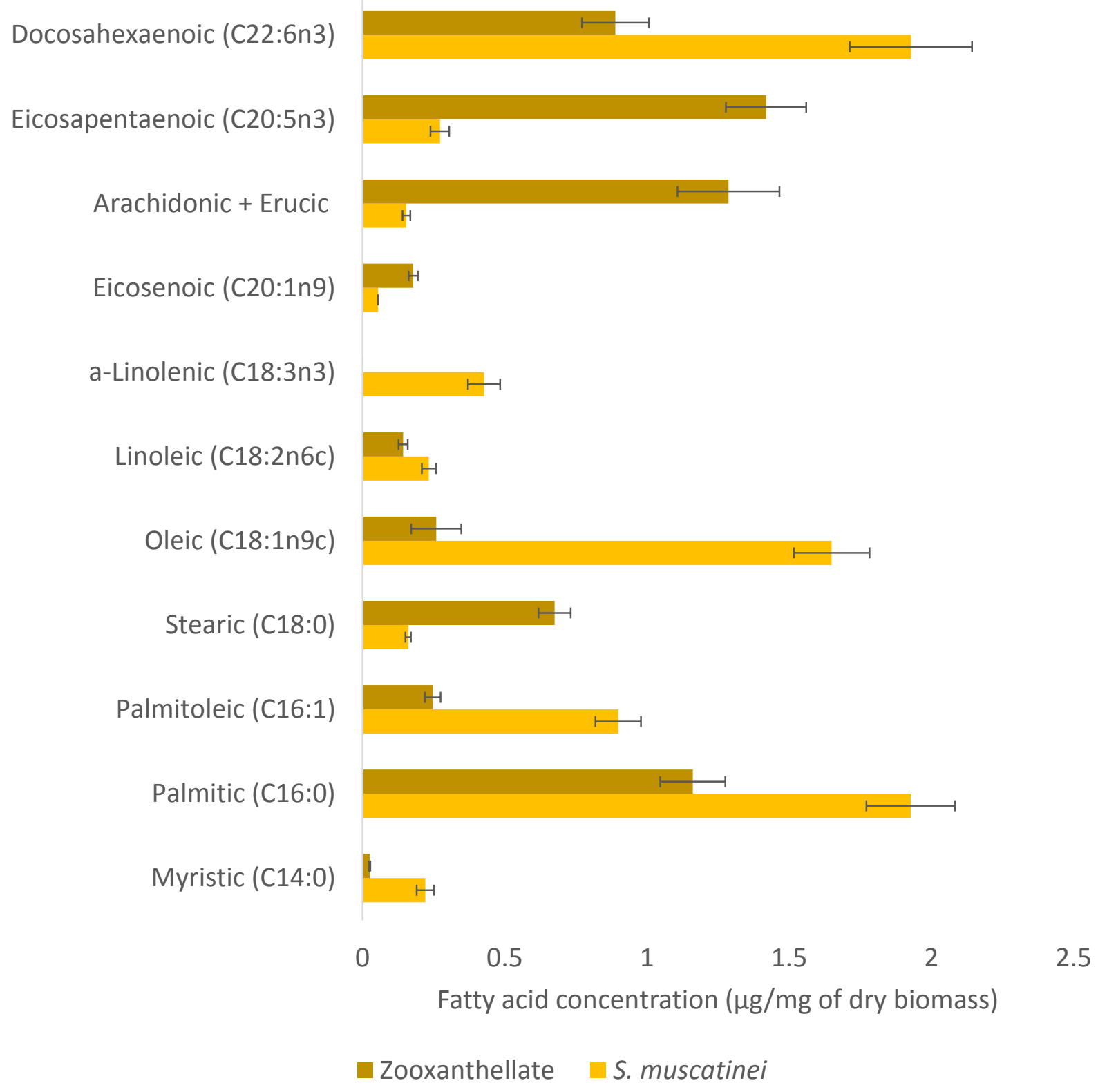

Figure 9. Fatty acid composition and concentration of Symbiodinium muscatinei and zooxanthellate Anthopleura elegantissima from Lawrence Point, Orcas Island. Fatty acids are ordered by length of the carbon chain. Standard error bars are shown. 


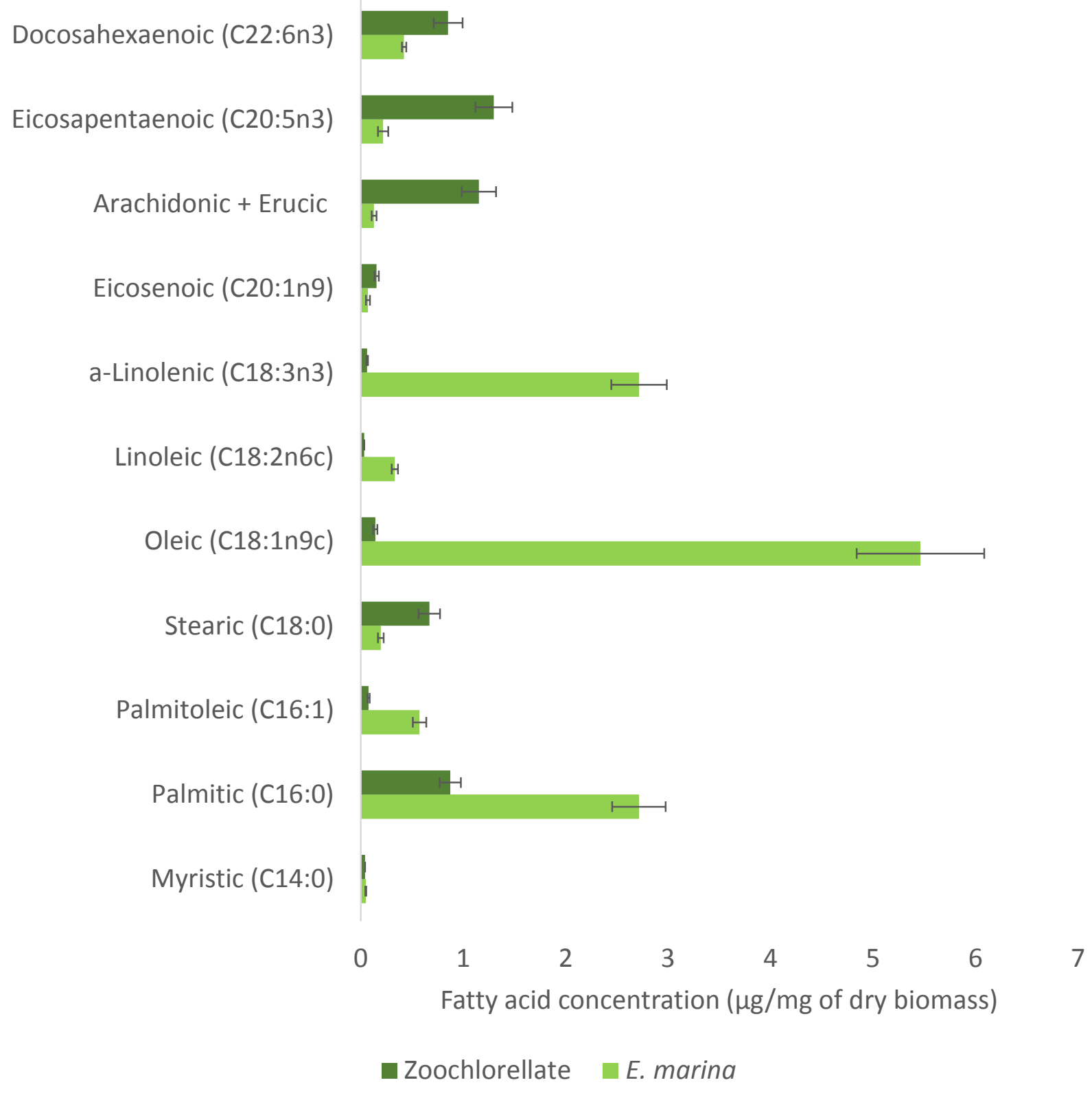

Figure 10. Fatty acid composition and concentration of Elliptochloris marina and zoochlorellate Anthopleura elegantissima from Lawrence Point, Orcas Island. Fatty acids are ordered by length of the carbon chain. Standard error bars are shown. 


\section{DISCUSSION}

\section{Fatty acid profiles of Symbiodinium muscatinei and Elliptochloris marina}

Our findings that palmitic acid, docosahexaenoic acid (DHA), and oleic acid were the most abundant fatty acids in S. muscatinei support previous research. Multiple studies indicate that palmitic acid and DHA are the major fatty acids in Symbiodinium isolated from corals (AlMoghrabi et al. 1995; Papina et al. 2003; Zhukova and Titlyanov 2006; Imbs et al. 2010). Other predominant fatty acids include stearic, stearidonic, palmitoleic, oleic, y-linolenic, arachidonic, and eicosapentaenoic acids (Suzuki et al. 2003; Papina et al. 2003; Zhukova and Titlyanov 2006; Díaz-Almeyda et al. 2010; Kneeland et al. 2013; Imbs et al. 2014). Although stearidonic acid, ylinolenic acid, and eicosapentaenoic acid (EPA) are considered marker polyunsaturated fatty acids for dinoflagellates (i.e. fatty acids synthesized by dinoflagellates but not by animals) (Imbs et al. 2014), we found low concentrations of EPA in S. muscatinei and did not detect stearidonic acid or y-linolenic acid in any of our samples. Other fatty acids such as octadecapentaenoic acid and docosapentaenoic acid (DPA) have also been suggested as marker fatty acids, but were not detected in our samples, although their concentration in Symbiodinium is generally very low (Papina et al. 2003; Imbs et al. 2014).

Here we present the first fatty acid profile of Elliptochloris marina, which has high levels of oleic, $\alpha$-linolenic, and palmitic acids. As expected, E. marina has a fatty acid composition similar to other chlorophytes, although lipid profiles vary among species. Tetraselmis sp. has a similar fatty acid composition to E. marina, with oleic acid as the most concentrated form, followed by $\alpha$-linolenic acid and palmitic acid (Patil et al. 2007). In Dunaliella spp., $\alpha$-linolenic acid and palmitic 
acid comprise about $60 \%$ of the total fatty acids (Viso and Marty 1993), whereas Chlorella sp. has high concentrations of $\alpha$-linolenic, palmitic, hexadecatrienoic, and linoleic acids (Zhukova and Aizdaicher 1995). These findings agree with our own, although we did not detect hexadecatrienoic acid. Also Dunaliella spp. and Chlorella sp. have low levels of oleic acid, which was the most abundant fatty acid in our E. marina samples. DHA and palmitoleic acid are consistently either absent or found in low concentrations in chlorophytes (Viso and Marty 1993; Zhukova and Aizdaicher 1995; Wiltshire et al. 2000; Patil et al. 2007).

We found that DHA, oleic acid, and $\alpha$-linolenic acid contributed most to the differences between S. muscatinei and E. marina. DHA is typically absent in chlorophytes, but very concentrated in dinoflagellates (Viso and Marty 1993; Zhukova and Aizdaicher 1995), leading to its use as a dinoflagellate biomarker (e.g. Bachok et al. 2006). The high concentrations of oleic and $\alpha$-linolenic acids in E. marina may explain why it performs better at lower temperatures and why zoochlorellate anemones are more abundant in low intertidal habitats and higher latitudes (Secord and Augustine 2000). Cell membrane fluidity decreases at low temperatures, presumably affecting the function of membrane transport proteins and ion gradients (Murata and Los 1997; Reay et al. 1999). The incorporation of unsaturated fatty acids into cell membranes restores membrane fluidity, because the "kinks" in their carbon chains reduce cell membrane density (Hazel 1997). Unsaturated fatty acids in the thylakoid membranes of cyanobacteria protect them from photoinhibition caused by low temperatures (Gombos et al. 1992; Gombos et al. 1994) and enhance lipid diffusion across the membrane (Sarcina et al. 2003). Organisms will synthesize unsaturated fatty acids to cope with low temperatures. For instance, a drop in temperature causes Nostoc sp. (Cyanobacteria) from Antarctic lakes to up-regulate the activity of enzymes 
that desaturate C18 fatty acids (Chintalapati et al. 2007). Lynch and Thompson (1984) found that shifting Dunaliella salina cultures from $30^{\circ} \mathrm{C}$ to $12^{\circ} \mathrm{C}$ led to an increase in oleic and $\alpha$-linolenic in the chloroplast phospholipids of the algal cells. Also, these fatty acids are more concentrated in macroalgae adapted to temperate waters than in macroalgae from warm waters (De Angelis et al. 2005; Colombo et al. 2006). However, a few studies suggest that chlorophytes accumulate key fatty acids such as oleic acid and palmitic acid during stress conditions, such as high irradiance, low temperatures, and nitrogen starvation (Mendoza et al. 1996; Mendoza et al. 1999; Zhekisheva et al. 2002). Whether the high levels of oleic acid we found in E. marina reflect their normal fatty acid composition, an adaptation to cold temperatures, or in hospite stress is unknown.

Fatty acid profiles of zooxanthellate, zoochlorellate, and aposymbiotic hosts

Although $A$. elegantissima is a temperate sea anemone, its overall fatty acid profiles match those of most tropical corals studied to date. Fatty acid content can be influenced by species, location, diet, and seasonality, but most corals have high concentrations of palmitic, stearic, elaidic, oleic, arachidonic, EPA, and DHA (Harland et al. 1993; Al-Moghrabi et al. 1995; Yamashiro et al. 1999; Oku et al. 2002; Bachok et al. 2006; Treignier et al. 2008; Imbs et al. 2010; Teece et al. 2011; Imbs 2013). Latyshev et al. (1991) analyzed the fatty acid composition of 14 calcifying coral species (with symbionts still in tissues) and found mainly palmitic, stearic, 18:1n9 (oleic and elaidic), arachidonic, EPA, and DHA. These findings agree well with our own, although most other studies did not detect erucic acid (or found it in very low concentrations) and found much lower concentrations of EPA. 
The lipid profile of $A$. elegantissima can be explained by its diet and de novo fatty acid synthesis without requiring input from symbionts. Animals can synthesize saturated fatty acids and monounsaturated fatty acids (MUFAs) from acetyl-CoA or from precursor fatty acids such as palmitic acid via desaturations (the addition of a double bond to the carbon chain) and elongations (the addition of two carbons to the chain), whereas polyunsaturated fatty acids (PUFAs) with $n-3$ and $n-6$ desaturations cannot be synthesized de novo by most animals and must be acquired through the diet (Dalsgaard et al. 2003). We found high concentrations of saturated fatty acids and MUFAs such as palmitic, stearic, elaidic, and erucic in A. elegantissima, and high concentrations of PUFAs including arachidonic, erucic, DHA, and especially, EPA. A. elegantissima feeds mainly on zooplankton, invertebrate larvae, and intertidal invertebrates, including mytilid bivalves (Sebens 1981). Most of the PUFAs and other fatty acids found in high levels in $A$. elegantissima, especially palmitic, palmitoleic, stearic, EPA, and DHA, are also dominant in marine zooplankton (Dalsgaard et al. 2003; Lee et al. 2006; Treignier et al. 2008; Seemann et al. 2013). Mytilid bivalves are also very rich in palmitic, palmitoleic, EPA and DHA (Zandee et al. 1980; Karakoltsidis et al. 1995; Murphy et al. 2002; Passi et al. 2002). Erucic acid, which was very concentrated in our samples but not in the corals studied to date, is found in high levels in some species of copepods and present in some mytilids (Karakoltsidis et al. 1995; Dalsgaard et al. 2003).

Research shows that PUFAs play an important role in invertebrate physiology. Arachidonic acid and EPA accumulate in the eggs of a species of sea pansy during months preceding spawning, indicating their likely role in gonad maturation (Pernet et al. 2002). EPA has also been linked to growth and egg production in the freshwater cladoceran Daphnia magna 
(Müller-Navarra et al. 2000). Similarly, DHA influences egg production in the calanoid copepod Temora longicornis (Evjemo et al. 2008). Thus, it seems likely that the greater concentrations of fatty acids in anemones hosting either symbiont would increase their fitness relative to aposymbiotic anemones.

Our finding that zooxanthellate hosts have greater total fatty acid concentrations than zoochlorellate hosts supports the idea that S. muscatinei is a better symbiont for the anemone. Previous research on A. elegantissima also suggests that zooxanthellate hosts have higher levels of non-polar lipids, cholesterol, and palmitic acid than do zoochlorellate hosts (Ponce-McDermott 2012). Interestingly, we found significantly greater concentrations of palmitic, palmitoleic, elaidic, and linoleic in zooxanthellate hosts than in zoochlorellate ones, but no differences in the PUFAs EPA and DHA. The former fatty acids can be synthesized by animals and their elevated concentrations in zooxanthellate hosts may be explained by greater contributions of (non-lipid) photosynthetic carbon from S. muscatinei. Carbon-containing photosynthates from Symbiodinium quickly accumulate into lipid droplets in the oral gastroderm of corals (Kopp et al. 2015). Also, corals synthesize lipids such as triglycerides and wax esters from glucose when exposed to light (Oku et al. 2003). Our results seem to confirm that S. muscatinei transfers more photosynthates to its host than E. marina does. Zooxanthellate hosts then use the additional carbon to synthesize fatty acids that are stored as triglycerides and wax esters, which are mainly composed of palmitic, stearic, and 18:1 (oleic/elaidic) acids in corals (Patton et al. 1983; Yamashiro et al. 1999).

The high concentration of fatty acids in zooxanthellate and zoochlorellate hosts compared to aposymbiotic sea anemones has three potential explanations, (i) fatty acid depletion by 
aposymbiotic anemones, (ii) variation in the diets of anemones in different symbiotic states, and (iii) translocation of fatty acids by symbiotic algae (discussed in the next section). Researchers have found significantly lower levels of wax esters and triacylglycerols in bleached corals (with low numbers of symbionts) than in healthy corals (Grottoli et al. 2004; Yamashiro et al. 2005). Corals store photosynthetic carbon from their symbionts as lipids to supply their daily metabolic needs (Bachar et al. 2007; Baumann et al. 2014) and start using up their triacylglycerol storage lipids immediately after bleaching (Rodrigues et al. 2008). Therefore, the lack of photosynthate input from symbionts may explain why aposymbiotic anemones had significantly depressed lipid levels. It is unlikely that feeding varied between anemones in different symbiotic states because we collected all sea anemones from the same site and at approximately the same tidal height. In addition, A. elegantissima symbiotic state has little effect on heterotrophic feeding (Hiebert and Bingham 2012), implying that the concentration of lipids acquired from the diet should be homogenous across symbiotic states. However, whether symbiont identity or presence influences host feeding should be further explored.

\section{Fatty acid profiles of hosts and their algal symbiont}

Several authors have suggested that algal symbionts translocate specific fatty acids to their hosts (Papina et al. 2003; Papina et al. 2007; Treignier et al. 2008; Mortillaro et al. 2009; Imbs et al. 2011). Although DHA is believed to be one of the fatty acids translocated, we found no correlation in its concentration in symbionts and hosts. We also found little difference in the levels of DHA between zooxanthellate and zoochlorellate hosts, even though this fatty acid was significantly more abundant in S. muscatinei than in E. marina. These findings suggest that DHA 
is not translocated by the symbionts but is obtained by sea anemones through the diet or via synthesis from precursor fatty acids.

Our finding that the concentration of palmitic acid in E. marina is positively correlated with that in zoochlorellate hosts has two potential explanations. First, it is possible that E. marina translocates palmitic acid to its zoochlorellate host. Presumably, E. marina with greater concentrations of palmitic acid are able to transfer more of this fatty acid to their host, resulting in greater concentrations of palmitic acid in host tissues. It is also possible that E. marina translocate other photosynthetic products (e.g. glucose) to their host, rather than lipids. Kopp et al. (2015) showed that anemones quickly accumulate photosynthates from their symbionts as lipid droplets and glycogen granules. Zooxanthellae also accumulate carbon from photosynthesis as lipids (Kopp et al. 2015), so the concentration of palmitic acid in E. marina may simply reflect its photosynthetic efficiency and the concentration of this fatty acid in host tissues reflects how much photosynthates it receives from E. marina. Overall, we find no evidence for the translocation of fatty acids from algal symbionts to anemone hosts.

\section{Conclusions and future research directions}

We show that the lipid composition of S. muscatinei from temperate A. elegantissima tracks that of zooxanthellae from tropical corals. We also present the first lipid profile of $E$. marina, which is rich in unsaturated fatty acids typically found in Chlorophytes. Whether the presence of these fatty acids gives E. marina greater resilience to colder temperatures and the extent to which the lipid profile of symbionts influences host ecology and life history are questions that warrant further research. We find that anemones hosting S. muscatinei have 
greater concentrations of most fatty acids than do anemones hosting E. marina, suggesting that the former is a more favorable symbiont for the host. The difference in total fatty acids of anemones in these two symbiotic states is not significant, so it seems that even in the summer, the greater density E. marina in host tissues offsets the higher productivity of S. muscatinei, as suggested by Engebretson and Muller-Parker (1999). Our results suggest that sea anemones lacking symbionts are at a disadvantage, possessing significantly lower concentrations of lipids. Future studies of dynamics of multi-symbiont system, symbiont switching and bleaching should take care to analyze only host tissues and not host tissues still containing symbionts given differences in the lipid composition of each. Further research is needed on the role of fatty acids in cnidarian metabolism, development, and reproduction to shed light on how hosts are affected by symbiont loss events such as coral bleaching. 


\section{REFERENCES}

Al-Moghrabi S, Allemand D, Couret JM, Jaubert J (1995) Fatty acids of the scleractinian coral Galaxea fascicularis: effect of light and feeding. J Comp Physiol B 165:183-192. doi: 10.1007/BF00260809

De Angelis L, Risé P, Giavarini F, et al. (2005) Marine macroalgae analyzed by mass spectrometry are rich sources of polyunsaturated fatty acids. J Mass Spectrom 40:1605-1608. doi: 10.1002/jms.962

Bachar A, Achituv Y, Pasternak Z, Dubinsky Z (2007) Autotrophy versus heterotrophy: The origin of carbon determines its fate in a symbiotic sea anemone. J Exp Mar Bio Ecol 349:295-298. doi: 10.1016/j.jembe.2007.05.030

Bachok Z, Mfilinge P, Tsuchiya M (2006) Characterization of fatty acid composition in healthy and bleached corals from Okinawa, Japan. Coral Reefs 25:545-554. doi: 10.1007/s00338-0060130-9

Baumann J, Grottoli AG, Hughes AD, Matsui Y (2014) Photoautotrophic and heterotrophic carbon in bleached and non-bleached coral lipid acquisition and storage. J Exp Mar Bio Ecol 461:469-478. doi: 10.1016/j.jembe.2014.09.017

Bergschneider $\mathrm{H}$, Muller-Parker G (2008) Nutritional role of two algal symbionts in the temperate sea anemone Anthopleura elegantissima Brandt. Biol Bull 215:73-88.

Bligh EG, Dyer WJ (1959) A rapid method of total lipid extraction and purification. Can J Biochem Physiol 37:911-917. doi: 10.1139/059-099

Chen W-NU, Kang H-J, Weis VM, et al. (2011) Diel rhythmicity of lipid-body formation in a coralSymbiodinium endosymbiosis. Coral Reefs 31:521-534. doi: 10.1007/s00338-011-0868-6

Chintalapati S, Prakash JSS, Singh AK, et al. (2007) Desaturase genes in a psychrotolerant Nostoc sp. are constitutively expressed at low temperature. Biochem Biophys Res Commun 362:8187. doi: 10.1016/j.bbrc.2007.07.150

Colombo ML, Risè P, Giavarini F, et al. (2006) Marine macroalgae as sources of polyunsaturated fatty acids. Plant Foods Hum Nutr 61:67-72. doi: 10.1007/s11130-006-0015-7

Dalsgaard J, St. John M, Kattner G, et al. (2003) Fatty acid trophic markers in the pelagic marine environment. Adv Mar Biol 46:225-340. doi: 10.1016/S0065-2881(03)46005-7 
Díaz-Almeyda E, Thomé PE, El Hafidi M, Iglesias-Prieto R (2010) Differential stability of photosynthetic membranes and fatty acid composition at elevated temperature in Symbiodinium. Coral Reefs 30:217-225. doi: 10.1007/s00338-010-0691-5

Engebretson HP, Muller-Parker G (1999) Translocation of photosynthetic carbon from two algal symbionts to the sea anemone Anthopleura elegantissima. Biol Bull 197:72-81.

Evjemo JO, Tokle N, Vadstein O, Olsen Y (2008) Effect of essential dietary fatty acids on egg production and hatching success of the marine copepod Temora longicornis. J Exp Mar Bio Ecol 365:31-37. doi: 10.1016/j.jembe.2008.07.032

Folch J, Lees M, Sloane Stanley G (1957) A simple method for the isolation and purification of total lipides from animal tissues. J Biol Chem 221:497-509.

Gombos Z, Wada H, Murata N (1992) Unsaturation of fatty acids in membrane lipids enhances tolerance of the cyanobacterium Synechocystis PCC6803 to low-temperature photoinhibition. Proc Natl Acad Sci U S A 89:9959-9963. doi: 10.1073/pnas.89.20.9959

Gombos Z, Wada H, Murata N (1994) The recovery of photosynthesis from low-temperature photoinhibition is accelerated by the unsaturation of membrane lipids: a mechanism of chilling tolerance. Proc Natl Acad Sci U S A 91:8787-8791. doi: 10.1073/pnas.91.19.8787

Grottoli AG, Rodrigues $\amalg$, Juarez C (2004) Lipids and stable carbon isotopes in two species of Hawaiian corals, Porites compressa and Montipora verrucosa, following a bleaching event. Mar Biol 145:621-631. doi: 10.1007/s00227-004-1337-3

Hammer $\varnothing$, Harper DAT, Ryan PD (2001) PAST: Paleontological Statistics software package for education and data analysis. Palaeontol Electron 4:9.

Harland AD, Navarro JC, Spencer Davies P, Fixter LM (1993) Lipids of some Caribbean and Red Sea corals: total lipid, wax esters, triglycerides and fatty acids. Mar Biol 117:113-117. doi: 10.1007/BF00346432

Hazel JR (1997) Thermal Adaptation in Biological Membranes: Beyond Homeoviscous Adaptation. Adv Mol Cell Biol 19:57-101. doi: 10.1016/S1569-2558(08)60075-2

Hiebert TC, Bingham BL (2012) The effects of symbiotic state on heterotrophic feeding in the temperate sea anemone Anthopleura elegantissima. Mar Biol 159:939-950. doi: 10.1007/s00227-011-1871-8

Imbs AB (2013) Fatty acids and other lipids of corals: Composition, distribution, and biosynthesis. Russ J Mar Biol 39:153-168. doi: 10.1134/S1063074013030061 
Imbs AB, Yakovleva IM, Dautova TN, et al. (2014) Diversity of fatty acid composition of symbiotic dinoflagellates in corals: evidence for the transfer of host PUFAs to the symbionts. Phytochemistry 101:76-82. doi: 10.1016/j.phytochem.2014.02.012

Imbs AB, Yakovleva IM, Latyshev NA, Pham LQ (2011) Biosynthesis of polyunsaturated fatty acids in zooxanthellae and polyps of corals. Russ J Mar Biol 36:452-457. doi: 10.1134/S1063074010060076

Imbs AB, Yakovleva IM, Pham LQ (2010) Distribution of lipids and fatty acids in the zooxanthellae and host of the soft coral Sinularia sp. Fish Sci 76:375-380. doi: 10.1007/s12562-009-0213y

Jiang P-L, Pasaribu B, Chen C-S (2014) Nitrogen-deprivation elevates lipid levels in Symbiodinium spp. by lipid droplet accumulation: morphological and compositional analyses. PLoS One 9:e87416. doi: 10.1371/journal.pone.0087416

Karakoltsidis P a., Zotos A, Constantinides SM (1995) Composition of the Commercially Important Mediterranean Finfish, Crustaceans, and Molluscs. J Food Compos Anal 8:258-273. doi: 10.1006/jfca.1995.1019

Kneeland J, Hughen K, Cervino J, et al. (2013) Lipid biomarkers in Symbiodinium dinoflagellates: new indicators of thermal stress. Coral Reefs 32:923-934. doi: 10.1007/s00338-013-1076-3

Kopp C, Domart-Coulon I, Escrig S, et al. (2015) Subcellular investigation of photosynthesis-driven carbon and nitrogen assimilation and utilization in the symbiotic reef coral Pocillopora damicornis. MBio 6:1-9. doi: 10.1128/mBio.02299-14.Editor

LaJeunesse T, Trench R (2000) Biogeography of two species of Symbiodinium (Freudenthal) inhabiting the intertidal sea anemone Anthopleura elegantissima (Brandt). Biol Bull 199:126-34.

Latyshev N, Naumenko N, Svetashev V, Latypov Y (1991) Fatty acids of reef-building corals. Mar Ecol Prog Ser 76:295-301.

Lee RF, Hagen W, Kattner G (2006) Lipid storage in marine zooplankton. Mar Ecol Prog Ser 307:273-306. doi: Doi 10.3354/Meps307273

Lesser MP, Stat M, Gates RD (2013) The endosymbiotic dinoflagellates (Symbiodinium sp.) of corals are parasites and mutualists. Coral Reefs 32:603-611. doi: 10.1007/s00338-013-1051$\mathrm{z}$

Leuzinger S, Anthony KRN, Willis BL (2003) Reproductive energy investment in corals: scaling with module size. Oecologia 136:524-31. doi: 10.1007/s00442-003-1305-5 
Lewis LA, Muller-Parker G (2004) Phylogenetic placement of "zoochlorellae" (Chlorophyta), algal symbiont of the temperate sea anemone Anthopleura elegantissima. Biol Bull 207:87-92.

Loram J, Trapido-Rosenthal H, Douglas A (2007) Functional significance of genetically different symbiotic algae Symbiodinium in a coral reef symbiosis. Mol Ecol 16:4849-57. doi: 10.1111/j.1365-294X.2007.03491.x

Luo Y-J, Wang L-H, Chen W-NU, et al. (2009) Ratiometric imaging of gastrodermal lipid bodies in coral-dinoflagellate endosymbiosis. Coral Reefs 28:289-301. doi: 10.1007/s00338-0080462-8

Lynch D, Thompson G (1984) Chloroplast Phospholipid Molecular Species Alterations during Low Temperature Acclimation in Dunaliella. Plant Physiol 74:198-203. doi: 10.1104/pp.74.2.198

Mendoza H, Jiménez Del Río M, García Reina G, Ramazanov Z (1996) Low-temperature induced B-carotene and fatty acid synthesis, and ultrastructural reorganization of the chloroplast in Dunaliella salina (Chlorophyceae). Eur J Phycol 31:329-331. doi: 10.1080/09670269600651551

Mendoza H, Martel a., Jiménez Del Río M, García Reina G (1999) Oleic acid is the main fatty acid related with carotenogenesis in Dunaliella salina. J Appl Phycol 11:15-19. doi: 10.1023/A:1008014332067

Mieog JC, Olsen JL, Berkelmans R, et al. (2009) The roles and interactions of symbiont, host and environment in defining coral fitness. PLoS One 4:e6364. doi: 10.1371/journal.pone.0006364

Mortillaro JM, Pitt K a., Lee SY, Meziane T (2009) Light intensity influences the production and translocation of fatty acids by zooxanthellae in the jellyfish Cassiopea sp. J Exp Mar Bio Ecol 378:22-30. doi: 10.1016/j.jembe.2009.07.003

Müller-Navarra DC, Brett MT, Liston a M, Goldman CR (2000) A highly unsaturated fatty acid predicts carbon transfer between primary producers and consumers. Nature 403:74-77. doi: $10.1038 / 47469$

Murata N, Los DA (1997) Membrane Fluidity and Temperature Perception. Plant Physiol 115:875879. doi: 10.1104/pp.115.3.875

Murphy KJ, Mooney BD, Mann NJ, et al. (2002) Lipid, FA, and sterol composition of New Zealand green lipped mussel (Perna canaliculus) and Tasmanian blue mussel (Mytilus edulis). Lipids 37:587-595. doi: 10.1007/s11745-002-0937-8

Oku H, Yamashiro H, Onaga K, et al. (2002) Lipid distribution in branching coral Montipora digitata. Fish Sci 68:517-522. doi: 10.1046/j.1444-2906.2002.00456.x 
Oku H, Yamashiro H, Onaga K (2003) Lipid biosynthesis from [14C]-glucose in the coral Montipora digitata. Fish Sci 69:625-631. doi: 10.1046/j.1444-2906.2003.00665.x

Papina M, Meziane T, van Woesik R (2007) Acclimation effect on fatty acids of the coral Montipora digitata and its symbiotic algae. Comp Biochem Physiol B Biochem Mol Biol 147:583-9. doi: 10.1016/j.cbpb.2007.02.011

Papina M, Meziane T, van Woesik R (2003) Symbiotic zooxanthellae provide the host-coral Montipora digitata with polyunsaturated fatty acids. Comp Biochem Physiol Part B Biochem Mol Biol 135:533-537. doi: 10.1016/S1096-4959(03)00118-0

Pasaribu B, Lin IP, Tzen JTC, et al. (2014) SLDP: a Novel Protein Related to Caleosin Is Associated with the Endosymbiotic Symbiodinium Lipid Droplets from Euphyllia glabrescens. Mar Biotechnol 16:560-71. doi: 10.1007/s10126-014-9574-z

Passi S, Cataudella S, Di Marco P, et al. (2002) Fatty acid composition and antioxidant levels in muscle tissue of different Mediterranean marine species of fish and shellfish. J Agric Food Chem 50:7314-7322.

Patil V, Källqvist T, Olsen E, et al. (2007) Fatty acid composition of 12 microalgae for possible use in aquaculture feed. Aquac Int 15:1-9. doi: 10.1007/s10499-006-9060-3

Patton JS, Battey JF, Rigler MW, et al. (1983) A comparison of the metabolism of bicarbonate 14C and acetate $1-14 \mathrm{C}$ and the variability of species lipid compositions in reef corals. Mar Biol 75:121-130. doi: 10.1007/BF00405994

Peng S-E, Chen C-S, Song Y-F, et al. (2012) Assessment of metabolic modulation in free-living versus endosymbiotic Symbiodinium using synchrotron radiation-based infrared microspectroscopy. Biol Lett 8:434-7. doi: 10.1098/rsbl.2011.0893

Peng S-E, Chen W-NU, Chen H-K, et al. (2011) Lipid bodies in coral-dinoflagellate endosymbiosis: proteomic and ultrastructural studies. Proteomics 11:3540-55. doi: 10.1002/pmic. 201000552

Pernet V, Gavino V, Gavino G, Anctil M (2002) Variations of lipid and fatty acid contents during the reproductive cycle of the anthozoan Renilla koellikeri. J Comp Physiol B Biochem Syst Environ Physiol 172:455-465. doi: 10.1007/s00360-002-0268-x

Ponce-McDermott MR (2012) Lipids of the sea anemone Anthopleura elegantissima: season and symbiont affect content and fractionation. Western Washington University

Reay DS, Nedwell DB, Priddle J, Ellis-Evans JC (1999) Temperature dependence of inorganic nitrogen uptake: Reduced affinity for nitrate at suboptimal temperatures in both algae and bacteria. Appl Environ Microbiol 65:2577-2584. 
Rodrigues $\amalg$, Grottoli AG, Pease TK (2008) Lipid class composition of bleached and recovering Porites compressa Dana, 1846 and Montipora capitata Dana, 1846 corals from Hawaii. J Exp Mar Bio Ecol 358:136-143. doi: 10.1016/j.jembe.2008.02.004

Sarcina M, Murata N, Tobin MJ, Mullineaux CW (2003) Lipid diffusion in the thylakoid membranes of the cyanobacterium Synechococcus sp.: Effect of fatty acid desaturation. FEBS Lett 553:295-298. doi: 10.1016/S0014-5793(03)01031-7

Sebens KP (1981) The allometry of feeding, energetics, and body size in three sea anemone species. Biol Bull 161:152-171.

Secord D, Augustine L (2000) Biogeography and microhabitat variation in temperate algalinvertebrate symbioses: zooxanthellae and zoochlorellae in two Pacific intertidal sea anemones, Anthopleura elegantissima and A. xanthogrammica. Invertebr Biol 119:139-146. doi: $10.1111 / \mathrm{j} .1744-7410.2000 . \mathrm{tb00002.x}$

Secord D, Muller-Parker G (2005) Symbiont distribution along a light gradient within an intertidal cave. Limnol Oceanogr 50:272-278. doi: 10.4319/lo.2005.50.1.0272

Seemann J, Sawall Y, Auel H, Richter C (2013) The use of lipids and fatty acids to measure the trophic plasticity of the coral Stylophora subseriata. Lipids 48:275-86. doi: 10.1007/s11745012-3747-1

Stat M, Morris E, Gates RD (2008) Functional diversity in coral-dinoflagellate symbiosis. Proc Natl Acad Sci U S A 105:9256-61. doi: 10.1073/pnas.0801328105

Stimson JS (1987) Location, quantity and rate of change in quantity of lipids in tissue of Hawaiian hermatypic corals. Bull Mar Sci 41:889-904.

Suzuki M, Watanabe K, Fujiwara S, et al. (2003) Isolation of Peridinin-Related Norcarotenoids with Cell Growth- Inhibitory Activity from the Cultured Dinoflagellate of Symbiodinium sp ., a Symbiont of the Okinawan Soft Coral Clavularia viridis, and Analysis of Fatty Acids of the Dinoflagellate. Chem Pharm Bull 51:724-727.

Teece MA, Estes B, Gelsleichter E, Lirman D (2011) Heterotrophic and autotrophic assimilation of fatty acids by two Scleractinian corals, Montastraea faveolata and Porites astreoides. Limnol Oceanogr 56:1285-1296. doi: 10.4319/lo.2011.56.4.1285

Treignier C, Grover R, Ferrier-Pagès C, Tolosa I (2008) Effect of light and feeding on the fatty acid and sterol composition of zooxanthellae and host tissue isolated from the scleractinian coral Turbinaria reniformis. Limnol Oceanogr 53:2702-2710. doi: 10.4319/lo.2008.53.6.2702 
Verde EA, McCloskey LR (2001) A comparative analysis of the photobiology of zooxanthellae and zoochlorellae symbiotic with the temperate clonal anemone Anthopleura elegantissima (Brandt). Mar Biol 138:477-489. doi: 10.1007/s002270000490

Verde EA, McCloskey LR (2002) A comparative analysis of the photobiology of zooxanthellae and zoochlorellae symbiotic with the temperate clonal anemone Anthopleura elegantissima (Brandt). Mar Biol 141:225-239. doi: 10.1007/s00227-002-0824-7

Verde EA, McCloskey LR (1996) Photosynthesis and respiration of two species of algal symbionts in the anemone Anthopleura elegantissima (Brandt) (Cnidaria; Anthozoa). J Exp Mar Bio Ecol 195:187-202. doi: 10.1016/0022-0981(95)00080-1

Viso A-C, Marty J-C (1993) Fatty acids from 28 marine microalgae. Phytochemistry 34:1521-1533.

Ward S (1995) Two patterns of energy allocation for growth, reproduction and lipid storage in the scleractinian coral Pocillopora damicornis. Coral Reefs 14:87-90. doi: 10.1007/BF00303428

Wiltshire $\mathrm{KH}$, Boersma M, Möller A, Buhtz H (2000) Extraction of pigments and fatty acids from the green alga Scenedesmus obliquus (Chlorophyceae). Aquat Ecol 34:119-126. doi: 10.1023/A:1009911418606

Yamashiro H, Oku H, Higa H, et al. (1999) Composition of lipids, fatty acids and sterols in Okinawan corals. Comp Biochem Physiol Part B Biochem Mol Biol 122:397-407. doi: 10.1016/S0305-0491(99)00014-0

Yamashiro $\mathrm{H}, \mathrm{Oku} \mathrm{H}$, Onaga $\mathrm{K}$ (2005) Effect of bleaching on lipid content and composition of Okinawan corals. Fish Sci 71:448-453.

Yellowlees D, Rees TA V, Leggat W (2008) Metabolic interactions between algal symbionts and invertebrate hosts. Plant, Cell Environ 31:679-94. doi: 10.1111/j.1365-3040.2008.01802.x

Zandee DI, Kluytmans JH, Zurburg W, Pieters H (1980) Seasonal variations in biochemical composition of Mytilus edulis with reference to energy metabolism and gametogenesis. Netherlands J Sea Res 14:1-29. doi: 10.1016/0077-7579(80)90011-3

Zhekisheva M, Boussiba S, Khozin-Goldberg I, et al. (2002) Accumulation of oleic acid in Haematococcus pluvialis (Chlorophyceae) under nitrogen starvation or high light is correlated with that of astaxanthin esters. J Phycol 38:325-331. doi: 10.1046/j.15298817.2002.01107.x

Zhukova N V, Aizdaicher NA (1995) Fatty acid composition of 15 species of marine microalgae. Phytochemistry 39:351-356. 
Zhukova N V., Titlyanov EA (2006) Effect of light intensity on the fatty acid composition of dinoflagellates symbiotic with hermatypic corals. Bot Mar 49:339-346. doi: 10.1515/BOT.2006.041 